\title{
Measuring Efficacy and Pattern of Preferences When Using Call; a Study with Special Reference to Esl Learners Of Uttrakhand Technical University
}

\author{
Ms. DiptiSrivastava*, Dr. Ruby Gupta \\ Assistant Professor DIT UniversityDehradun \\ **Professor( Humanities ) DIT University, Dehradun
}

\begin{abstract}
Computer Assisted language Learning has now become an accepted form of teaching language. It is widely acknowledged that the use of computers have positive impact on the students. Yet it has always been a matter of a question why the impact of CALL has been different for different students. There have been numerous studies on students and teachers' attitude and perception towards CALL but there has been only limited studies exploring students preferences and learning experience.

The present study tries to explore students' perspectives and personal preference while using CALL. The main objective of the paper was to explore how students feel during CALL and also to measure the efficacy of CALL on students with different medium of study previously. This is a mix of both quantitative and qualitative research based on the information obtained from a questionnaire survey of technical students pursuing B.Tech from Uttrakhand Technical University, Dehradun, India. The survey was followed by a round of interviews of students. The findings of the study have shown that there is a significant association between the students achievement in language proficiency and the medium of their previous study.

The responses of the students revealed certain pattern of preferences of the students like, the hours preferred, the technique adopted for using CALL material, Skills developed,exercises liked by them and their opinion about error correction via computers.
\end{abstract}

Keywords:CALL, CBT, ESL, Attitude and Learning Experience

\section{Introduction:}

The emerging trend of educational technologies has brought a paradigm shift in the field education. Following this trend of language teaching the Technical universities and other Higher Education institutions, throughout India and Uttarakhand, have heavily invested in technology to support teaching and to enhance students' learning experience and output. However, the learning experience and outcomes in such environments are not always as expected: students may fail to use the facilities available to them, language teachers may show some resistance towards new approaches to language teaching and learning, and university authorities may be reluctant to provide adequate support, technical or otherwise. Despite these difficulties, many new teaching trends have been evolved and many enthusiast teachers continue to use it. Computer assisted language learning is one of the most talked language teaching approach. Computers have been incorporated in manyform for teaching and learning languages but its impact has been different for different language skills different age group learner and various other factors. This research is in an attempt to measure the efficacy and pattern of preferences while using CALL.

Many significant works have been done in the area yet it has always been a matter of a question why the impact of CALL has been different for different students. There have been numerous studies on students and teachers' attitude and perception towards CALL but there has been only limited studies exploring students' preferences and learning experience.

Computer Assisted Language Learning: Computer Aided/Assisted Language Learning (CALL) is a relatively new and rapidly evolving academic field of computer delivered instruction. It explores the role of information and communication technologies in language learning and teaching, CALL activities exploit improved technology to produce highly interactive learning environments, providing effective support for the acquisition of listening, speaking, reading, and writing skills. The use of computers in language teaching, had started way back in 1960 in western countries which was named as Computer Assisted Language Learning precisely CALL. The concept of using Computer in Language learning has started since 1960. This trend has been led by the establishment of Language laboratories during the 1960s, which were initially introduced with cassette players and headphones into educational institutions. The use of this kind of lab grew rapidly in the late 1960s and 
1970s, but this fashion faded very soon. Later, 'the digital language labs' were introduced, still following the traditional language teaching format, such as teacher monitoring and teacher centric.

\section{Literature Review :}

The research in the field of CALL has started ever since the time CALL came into its existence but it did not focus much on how do learners feel about it. There has been a significant amount of research that explores the role of computers in the learning and teaching process and its impact in the classroom (Chapelle, 2001; Dhaif, 1989; Galavis, 1998; Gruich, 2002; Hubbard, 1996; Kenning \& Kenning, 1983; Levy, 1997; MuirHerzig, 2003; Pennington, 1996; Schofield, 1995).Most CALL empirical studies with different perspectives of SLA focus on the effectiveness of the medium itself, particularly in comparison with conventional teaching tools . In short, CALL is seen as a treatment given to the learner, and the effect of the treatment on learning is measured later on.

Not all research gave favorable response but some of them also projected certain resistance to using computer-based learning which is usually attributed to the technology phobia. Bloom (1985) affirms that student resistance to using computers in learning is related to computer anxiety or computer phobia. However, this study was conducted more than twenty years ago. Since that period, CALL has been maturing and computers have been popular and used by students all over the world. According to Bernt, Bugbee, and Alan (1990), as the computer becomes part of one's everyday life, potential users may base their attitude toward the computer and the advantages it affords in a particular setting rather than on their reactions to their fears and anxiety of the computers. Bernt et al. (1990) conclude that benefits of computer applications play a leading role in affecting one's attitude toward using computers. One of the best ways to evaluate CALL is through the investigation of students and teachers opinion, perception, belief and attitude. However the research towards this angle (Perception Attitude and Motivation ) were not initiated by this time.

Most studies have concentrated on the efficacy of CALL, based their findings on case, qualitative and research-based studies. Furstenberg (1997) argues that CALL is a tool which enhances learner-learner interaction. In the same line, Warschauer (1997) thinks that CALL helps learners use language in authentic situations. The teacher, therefore, should involve learners in well-prepared computer-based activities, and use well-established methods and techniques. Kelm (1998) also points out that CALL helps learners use language in authentic situations, promotes communication among learners, provides them with feedback about their errors, and allows socialization and communication between them.

Regarding classroom CALL applications, some motivational studies were able to observe supportive outcomes that show the effectiveness of CALL (Beauvois, 1995; Warschauer, 1996; García\& Arias, 2000; Appel\&Gilabert, 2002; Chang, 2005; Jarrell \&Freiermuth, 2005.). However, whether or not the results of these studies are applicable for self-study language learning is still not fully known.

The results of Lam's study and several others (Albion, 1999; Baylor \& Ritchie, 2002; Clark, 2000; Dusick, 1998; Ertmer, Addison, Lane, Ross, and Woods, 1999; Gruich, 2002; Kemp, 2002; Marcinkiewicz, 1994) suggest that teachers' attitudes toward using computer technology resources influence their acceptance and use of these resources. Furthermore, positive attitudes toward these computer technology resources might develop depending on opportunities, facilities and training provided to users of them (Akbaba\&Kurubacak, 1998; Clark, 2000; Dexter, Anderson, \& Becker 1999; Jones, 2001; Herman, 2002).

Salaberry (2001) analyzed the articles included in Modern Language Journal about the use of technology including CALL for second language learning and teaching. He believes that technology-enhanced learning is revolutionary from the pedagogical point of view. However, the results that Salaberry report about the use of CALL show that the effect of technology on second language learning and teaching is not clear. He identifies some criteria for creating a positive effect for technology. The most important of them are evaluating technology according to its pedagogical use and integrating technology successfully in the curriculum.

CALL has been reported to have a positive effect on learners performance and attitude. Ayres (2002) states that CALL is relevant to students needs as it provides them with useful information. According to his findings, CALL should be used more frequently in different language courses. This can be attributed to the fact that CALL environment is a stress-free atmosphere and more relaxed than the classroom (Murphy, 1997; Roed, 2003). Furthermore, more interaction between learners occurs in computer-based learning because students depend on themselves.

Because of its reported positive effect on learning language skills, the use of technology as a medium has increased phenomenally in the last two decades (Greenfield, 2003). Computermediated language learning helps students develop their both productive and receptive skills.

Lasagabaster and Sierra (2003) believe that researchers should take into consideration students opinions when CALL programs are evaluated because students are potential contributors to the development of the language learning tools, and experts in their learning. Lasagabaster and Sierra also suggest conducting more studies 
regarding students insights and impressions, though several studies have been conducted in this regard. Many researchers support Findings of some studies on the use of call are contradictory.

\section{Methodology:}

The present study is an exploratory study which has been conducted by using random sampling. 300 samples have been taken from 10 different colleges of Uttarakhand Technical University. A descriptive research has been adopted to analyze and measure the effectiveness and the pattern of preferences using Computer assisted language learning, Since the study proposed to measure effectiveness of Computer assisted language learning and also the learning experience of the students with minimum or no variable so it is both a qualitative and quantitative research, Statistical tools have been applied to draw the accurate results. The study addressed the following research questions:

The Research Questions: The study employs computer aided language learning tools for a group of target students to generate effective/positive results of Language Learning experience among ESL learners of different proficiency levels.

1. Is there any significant difference in students' achievement in ESL between students from Hindi and English medium due to treatment of computers?

2. What is the pattern of preferences of ESL learners while using CALL?

Participants: The study has been conducted on students pursuing B.Tech or MCA at various colleges of Uttarakhand Technical University. The participant were from 10 different colleges of Uttarakhand Technical University

\section{Demographic Profile of the participants}

\begin{tabular}{|l|}
\hline Gender \\
\hline Male- 180 \\
\hline Female- 120 \\
\hline Age \\
\hline$>18$ years \\
\hline 18 -20 years \\
\hline$<20$ years \\
\hline
\end{tabular}

\begin{tabular}{|l|}
\hline Level of study \\
\hline UG \\
\hline PG \\
\hline
\end{tabular}

\begin{tabular}{|l|}
\hline Medium \\
\hline Hindi-86 \\
\hline English- 214 \\
\hline
\end{tabular}

Figure 1

Data Collection Instruments In this study, mainly two types of data collection methods were used: a questionnaire and face-to-face semi-structured interviews.

Questionnaire: The questionnaire used in the present study is a set of 25 questions both closed and open ended apart from this certain questions related to demographic profile are also required to fill-in. Section one in the questionnaires aimed to collect relevant information about participant's background: their age, gender, year of study, medium of study till $12^{\text {th }}$ and also the acquaintance with computer- assisted language learning.

The Second section intended to explore student's attitude towards computer- assisted learning through nine items. The first five items were directed to learn about participant's computer proficiency and the following items to learn about their anticipated problems occurring during learning. The other nine questions of this section tried to know the benefits earned though CALL in present and future, skills learnt and preferences during learning.

The third section of the questionnaire is a set of 7 subjective questions seeking scope of improvement in the existing Computer aided language learning classes and also the suggestions to make it more effective.

Interviews: The second tool used in the study was a semi- structured - interview. It is the most common pattern of a study using questionnaire and interview together.The interview questions were structured parallel to the sections in the questionnaire.

Procedure \&Data Analysis:The present study is a part of research work carried out for the doctorate degree. The samples undertaken in the study were B.Tech as well as M.C.A students of Uttrakhand Technical University. A total of 300 samples of mixed proficiency and geographical background have been involved in the study. They were first given questionnaire togive their responses based on their six months experience with CALL after another six months of study they were interviewed. The responses expressed in questionnaire as well as interviews were analyzed with the help of SPSS software, using chi-square Frequency Distribution and 
mean calculation which helped me to reach on certain conclusion. The findings of the study were helpful to answer the research questions.

In answer to the first research question i.eis there any significant difference in students' achievement in ESL between students from Hindi and English medium due to treatment of computers? The findings given below are on the basis of one very important question of the questionnaire which was ; What problem do you face while using CALL? In answer to which maximum students whose previous mode of instruction was Hindi, responded that they have difficulty in understanding the instruction. The table given below can clearly depict that There is a significant association between treatment of computer and students'( from different medium of education) achievement in ESL.

MOD * what problems do you face Cross tabulation
Count
\begin{tabular}{|ll|r|r|r|r|r|}
\hline \multirow{2}{*}{} & \multicolumn{4}{|c|}{ what problems do you face } \\
\cline { 3 - 7 } & & $\begin{array}{c}\text { Getting } \\
\text { used to of } \\
\text { computers }\end{array}$ & $\begin{array}{c}\text { Understanding } \\
\text { the instruction }\end{array}$ & $\begin{array}{c}\text { Reading } \\
\text { the } \\
\text { screen }\end{array}$ & $\begin{array}{c}\text { absence } \\
\text { of the } \\
\text { teacher }\end{array}$ & Total \\
\hline MOD & English & 18 & 31 & 133 & 32 & 214 \\
& Hindi & 17 & 25 & 10 & 34 & 86 \\
Total & & 48 & 158 & 28 & 67 & 300 \\
\hline
\end{tabular}

Table 1

We can observe from the above table that students' whose medium of instruction of previous study was Hindi realized a difficulty in understanding the instruction given my computers. On being checked through a significance testing using Chi - Square the difference was less than .05 which clearly depicts the strong association between mode of instruction and students achievement in a particular language proficiency.( see Table 2)

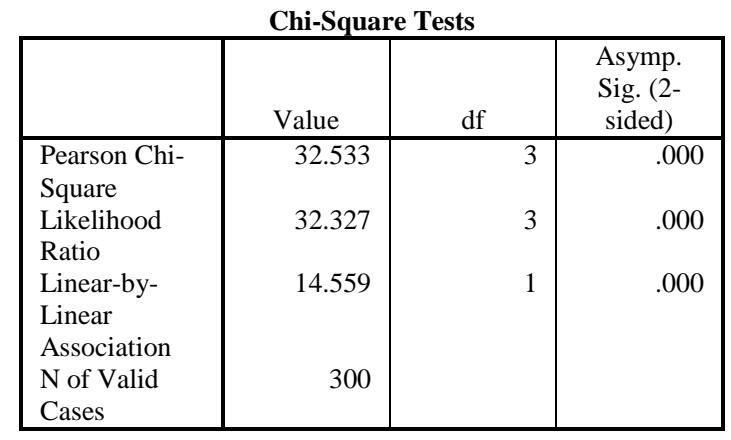

Table 2

The other findings were drawn from various other questions of the questionnaire. Pattern of preference can be analyzed on the basis of some question like:

Which hours are liked by you for the language lab? The respondent expressed their opinion as:

\begin{tabular}{|c|c|c|c|c|c|c|c|}
\hline Respondent & Morning & Evening & Afternoon & Total & $\mathbf{A} \%$ & B\% & $\mathrm{C} \%$ \\
\hline $\begin{array}{l}\text { MALE ENGLISH ( } \\
\text { UG) }\end{array}$ & 40 & 26 & 19 & 85 & 47.06 & 30.59 & 22.4 \\
\hline MALE Hindi ( UG) & 18 & 4 & 3 & 25 & 72.00 & 16.00 & 12.0 \\
\hline $\begin{array}{l}\text { FEMALE English ( } \\
\text { UG) }\end{array}$ & 15 & 6 & 14 & 35 & 42.86 & 17.14 & 40.0 \\
\hline FEMALE Hindi ( UG) & 5 & 6 & 14 & 25 & 20.00 & 24.00 & 56.0 \\
\hline $\begin{array}{l}\text { MALE ENGLISH ( } \\
\text { PG) }\end{array}$ & 29 & 5 & 1 & 35 & 82.86 & 14.29 & 2.9 \\
\hline MALE HINDI ( PG) & 23 & 8 & 4 & 35 & 65.71 & 22.86 & 11.4 \\
\hline $\begin{array}{l}\text { FEMALE ENGLISH( } \\
\text { PG) }\end{array}$ & 29 & 5 & 1 & 35 & 82.86 & 14.29 & 2.9 \\
\hline FEMALE HINDI( PG) & 9 & 7 & 9 & 25 & 36.00 & 28.00 & 36.0 \\
\hline Total & 168 & 67 & 65 & 300 & 56.00 & 22.33 & 21.7 \\
\hline
\end{tabular}


On the basis of the above table, we can see that $56 \%$ of the total sample says that they like using Language lab in Morning Hours, whereas 22.33 \& $21.7 \%$ sample says that they like using language lab in the evening and afternoon respectively.

If we observe the minute details, it is found that the PG students prefer morning hours than to evening or afternoon, whereas UG students liked the afternoon and the evening sessions.

In response to other questions like when working with exercise on the computer, which technique do you prefer?

It was foundthat $52.15 \%$ of the total sample, says that students like to choose their own exercise when practicing in language lab, $28.38 \%$ of the sample says that they like practice exercise set by teacher, where as $19.47 \%$ of the sample says that like they work on anything random.

If we observe the data separately by the categories we can see that the PG Male students who are from Hindi medium background they like their teacher to set their exercise.

A very important point which has emerge through this observation that students like, autonomy during their practice in the Language lab.

\section{Which type of exercise do you remember the most?}

It was found that $68 \%$ of the total sample says that they like Vocabulary learning with CALL $30 \%$ of the total sample says they like Language games. The percentage for spelling and grammar exercises and sentence restructuring were nominal. It was also observe that mostly PG students liked vocabulary.

Do you prefer the computer to give you some information about your grammatical errors?

It was found that $84 \%$ of the total sample prefers if they are corrected via computers only $16 \%$ reveal a negative opinion about it.

\section{Conclusion:}

Based on the above findings we can conclude that student's medium ofinstruction ofprevious study has a role to play in understanding instructions via computers. The responses given in the questionnaire as well as in interview helped finding a pattern of preferences while using Call which I think can be fruitful developing CALL materials or administrating CALL classes. This can alsobe concluded that students prefer autonomy up to some extent but they prefer if they are regulated or corrected via computers.

\section{Recommendation:}

It is recommended that there has to be separate classes or CALL material for students coming from different schooling background, The CALL material should be designed considering students need and preferences for conducive environment of teaching.

\section{References}

[1]. Davies, G., Hewer, S. (2001) Introduction to new technologies and how they can contribute to language learning and teaching. ICT4LT Project. Retrieved on October 23, 2007 from http://www.ict4lt.org/en/en mod1-1.htm

[2]. Levy, M. (1997).Computer-Assisted Language Learning: Context and Conceptualization. Oxford: Oxford University Press.

[3]. Taylor, M. B., \& Perez, L. M. (1989). Something to do on Monday. La Jolla, CA: Athelstan. p. 63.

[4]. Warschauer, M.(1999). CALL vs. Electronic Literacy: Reconceiving Technology in the Language Classroom. CLIT Research Forum. Retrieved on October 23, 2007 from http://www.linguanet,org.uk/research/resfor2/warsum1.html

[5]. Bax S. (2003) "CALL - past, present and future", System31:13-28 